Revista de la red interuniversitaria de estudios sobre las literaturas rioplatenses contemporáneas en Francia

19 | 2018

La rebelión de los hijos: el judaísmo en la literatura latinoamericana contemporánea entre tradición y asimilación

\title{
Juan Gelman y el hilo roto de la tradición
}

\section{Valentina Litvan}

\section{(2) OpenEdition}

Journals

Edición electrónica

URL: http://journals.openedition.org/lirico/6554

DOI: $10.4000 /$ lirico.6554

ISSN: 2262-8339

Editor

Réseau interuniversitaire d'étude des littératures contemporaines du Río de la Plata

Referencia electrónica

Valentina Litvan, « Juan Gelman y el hilo roto de la tradición », Cuadernos LIRICO [En línea], 19 | 2018 Puesto en línea el 20 enero 2019, consultado el 20 abril 2019. URL : http://journals.openedition.org/ lirico/6554; DOI : 10.4000/lirico.6554

Este documento fue generado automáticamente el 20 abril 2019.

\section{cc)}

Cuadernos LIRICO está distribuido bajo una Licencia Creative Commons Atribución-NoComercial-

SinDerivar 4.0 Internacional. 


\title{
Juan Gelman y el hilo roto de la tradición
}

\author{
Valentina Litvan
}

Pasamos del vientre materno a la lengua materna, de una matriz material a otra espiritual, que no nos abandonará hasta nuestra muerte. Juan Gelman

\section{Preliminares}

“Ningún testamento precede a nuestra herencia". Este aforismo de René Char ${ }^{1}$ daba pie a Hannah Arendt para explicar cómo los escritores y hombres de letras de la Resistencia, entre los que el poeta francés formaba parte, que habían sido capaces de atisbar la libertad durante los cuatro años de lucha cotidiana durante la guerra, no habían sabido sin embargo transmitir ese "tesoro" en el momento de la Liberación (1968: 4). Arendt sitúa el inicio de la tragedia en ese momento, ya no por circunstancias históricas sino porque, en la ausencia de una conciencia posterior capaz de cuestionar, de reflexionar, de contar la historia y de dar sentido a la acción, ésta caía en el olvido. A falta de nombrarlo, el acto queda incompleto, y el acontecimiento se pierde para siempre: "El hilo de la tradición está roto y no podremos restaurarlo. Lo que se ha perdido es la continuidad del pasado, pero un pasado fragmentario que ya no podemos valorar con certeza." (1981: 237) ${ }^{2}$ Para Hannah Arendt la modernidad se define justamente por esta ruptura con la tradición de la que el testamento es su metáfora:

El testamento o, por elucidar la metáfora, la tradición -que selecciona y nombra, que transmite y conserva, que indica dónde se halla el tesoro y cuál es su valorparece no tener continuidad en el tiempo sin asignación y que no haya, por consecuencia, humanamente hablando, ni pasado ni futuro, sino solo el devenir eterno del mundo y en él el ciclo biológico de los seres vivos. ${ }^{3}$

La idea de que se ha roto el hilo de la tradición puede trasponerse de manera específica a la modernidad judía. Así, Stéphane Mosès, en su libro sobre Rozensweig, Benjamin y Scholem, El ángel de la historia, plantea que la modernidad judía está ligada al movimiento 
de rechazo de la tradición que se inicia con la Emancipación ${ }^{4}$. Con la expresión "rebelión de los hijos", Mosès se refiere a la asimilación de los judíos, una evidente conquista y apertura para la Europa del s. XVIII (1790) que, sin embargo, podía significar paradójicamente su debilitamiento en cuanto a la transmisión de esa misma tradición. Es a lo que se refieren Benjamin y Scholem sobre Kafka en su correspondencia, cuando afirman que las criaturas de sus relatos ya no son capaces de entender una ley a la que sin embargo siguen estando sometidas ${ }^{5}$. Pero es sobre todo la situación paradójica de Kafka en su carta al padre, donde más que una confrontación y rechazo hacia el legado paterno, el escritor le reprocha precisamente no haber sabido transmitirle esa tradición, de la que sólo representaba el "simulacro" y la "formalidad".

A pesar de las especificidades de la situación de los judíos en América Latina, tierra de inmigración y de acogida en su fase de construcción de los estados-nación ${ }^{6}$, la pregunta por la ruptura del hilo de la tradición y sobre sus posibilidades de transmisión que se plantean Hannah Arendt y Stéphane Mosès en un contexto preciso, sigue siendo válida. Cabe preguntarse en este sentido cómo se articulan las dos tradiciones, nacional y judía, más allá de la utópica teoría del guión de una supuesta literatura judeo-argentina (Goldberg, Kovadlof, Senkman, Sosnowski...) y cómo se manifiesta la tensión que un doble legado implica siempre. Podemos preguntarnos, concretamente, qué pasa con la tradición judía en los escritores que de modo consciente o inconsciente, voluntario o involuntario, han olvidado, rechazado o reprimido, ese legado al integrarse y reconocerse, ante todo, en las literaturas nacionales, con la lengua nacional. A pesar de que desde una concepción normativa del judaísmo toda literatura es "apócrifa" (Philippe Zard, 2018), podemos seguir desvelando las huellas de una herencia que sigue estando presente, tal vez porque, como sugiere la imagen del vórtice de Benjamin retomada por Agamben, el origen siempre está presente:

[...] el vórtice del origen permanece hasta el final presente, acompaña nuestra existencia en cada instante, silenciosamente. En algunas ocasiones está más próximo, en otras se aleja hasta tal punto que no logramos asirlo ni escuchar su fuente secreta. Pero, en los momentos decisivos, nos toma y nos arrastra dentro de él y, entonces, de golpe, nos damos cuenta de que no somos más que un fragmento del inicio que continúa girando [...]. (Agamben: 53)

Se trata entonces de preguntarse por el judaísmo presente en las obras no en tanto marcas de pertenencia religiosa, sino como huella de origen, un origen al que no se puede retornar no porque no exista o sea inaccesible, sino porque el origen, según la concepción benjaminiana evocada, está en el presente histórico de cada uno. Lejos de la evocación nostálgica de un origen perdido, me interesa entender cómo funciona esa herencia en el presente. Y si a pesar de tratarse de textos literarios desligados de la religión sigo utilizando el término de judaísmo en lugar del de judeidad (Albert Memmi), es porque en ese vínculo con el origen me parece persistir, también desde su ausencia, una pregunta por cierta trascendencia -llámesele misterio o secreto de la transmisión- de la que, frente al discurso puramente comunicativo, la literatura puede seguir haciéndose eco ${ }^{7}$. Mi punto de partida tampoco es, entonces, el del judaísmo como vínculo social o comunitario -ese judaísmo puramente formal que Kafka califica de simulacro-, o el de una identidad que pudiera caer en esencialismo. Mi pregunta tiene que ver más bien con las posibilidades de transmisión que tiene el relato, es decir en qué medida el discurso literario sigue transmitiendo esa herencia de la tradición, y de qué manera, sobre todo cuando no se trata de una reivindicación de pertenencia. Una herencia de la que en muchos casos poco se sabe, pero a la que se interpela, para interrogarla, cuestionarla, y que deja sus huellas 
malgré soi en la escritura, a través de la lengua. La pregunta sería entonces qué pasa y qué se transmite, qué es lo que todavía queda, a pesar de uno. Me parece oportuno recordar en este sentido el midrash hasídico de tradición oral según el cual, aun después de haber perdido la capacidad para encender el fuego, de haber olvidado la plegaria y de no reconocer más el lugar en el bosque, esto es a pesar del olvido progresivo con las diferentes generaciones, el "milagro" se puede seguir realizando siempre que exista el relato:

Cuando el Baal Shem, el fundador del jasidismo, debía resolver una tarea difícil, iba a un determinado punto en el bosque, encendía un fuego, pronunciaba las oraciones y aquello que quería se realizaba. Cuando, una generación después, el Maguid de Mezritch se encontró frente al mismo problema, se dirigió a ese mismo punto en el bosque y dijo: "No sabemos ya encender el fuego, pero podemos pronunciar las oraciones", y todo ocurrió según sus deseos. Una generación después, Rabi Moshe Leib de Sasov se encontró en la misma situación, fue al bosque y dijo: "No sabemos ya encender el fuego, no sabemos pronunciar las oraciones, pero conocemos el lugar en el bosque, y eso debe ser suficiente". Y, en efecto, fue suficiente. Pero cuando, transcurrida otra generación, Rabi Israel de Rischin tuvo que enfrentarse a la misma tarea, permaneció en su castillo, sentado en su trono dorado, y dijo: "No sabemos ya encender el fuego, no somos capaces de recitar las oraciones y no conocemos siquiera el lugar en el bosque: pero de todo esto podemos contar la historia". Y, una vez más, con eso fue suficiente ${ }^{8}$.

Cuándo y cómo se revela el legado judío en la literatura secular enraizada en una nueva tradición nacional latinoamericana es lo que, en definitiva, pretendo abordar en este artículo, a partir de la obra de Juan Gelman. Qué formas persisten o cómo reaparecen y manifiestan esa herencia judía (en su caso íntima, familiar y literaria) que palpita en la lengua, modulándola y atravesándola, a menudo dejando sus marcas, pero también, en muchos casos, como ausencias significativas o tachaduras. Lo judío como origen ya no tiene entonces nada que ver con un fardo que se arrastra del pasado, sino con una presencia latente pero pronta a manifestarse en determinados momentos, renovada, para significar en el presente de la escritura.

\section{La transmisión discontinua o la reinvención de la tradición desde el exilio}

La poesía de Juan Gelman, primer hijo nacido en Argentina en 1930 en el seno de una familia de inmigrantes ucranianos, ha sido reconocida internacionalmente con numerosos galardones y ocupa un lugar central dentro del contexto nacional argentino. En la misma línea de Raúl González Tuñón, Gelman incorpora el habla porteña, el lunfardo y el tango, mediante los cuales se inserta en la tradición nacional y contribuye a la renovación del lenguaje poético argentino. Desde el principio la construcción de su obra está estrechamente ligada a su compromiso social y político como preocupaciones manifiestas en sus versos (sus inicios están vinculados al grupo "El pan duro"), y sólo tras su exilio en 1976 la tradición judía aparece de manera explícita para convertirse en un componente fundamental de su obra. Leonardo Senkman (2000 y artículo publicado en este número) ha estudiado en este sentido cómo con el exilio muchos escritores judíos latinoamericanos repitieron la experiencia del viaje de sus progenitores, pero en dirección opuesta. En los siguientes versos, Gelman tematiza el paralelismo invertido de este viaje:

XII 
Mi padre vino a América con una mano atrás y otra adelante, para tener bien alto el pantalón. Yo vine a Europa con una alma atrás y otra adelante, para tener bien alto el pantalón. Hay diferencias, sin embargo: él fue a quedarse, yo vine para volver.

¿Hay diferencias, sin embargo? Entre los dos fuimos, volvimos, y nadie sabe todavía adónde iremos a parar.

(de Bajo la lluvia ajena)

El exilio de Gelman despierta reminiscencias de orden familiar, pero también históricopolíticas y existenciales, que plasman sus poemas a partir de entonces. En ocasión de la entrega del premio Cervantes al poeta argentino José Ángel Valente ya hablaba de la doble condición del exilio en Gelman, histórico-política y existencial, cuando decía que "habría que hablar de un doble exilio [...]: el histórico, implícito en lo lingüístico, y el existencial, tan explícito en el compromiso político de otras épocas y en el tránsito de país en país." Es a partir de su exilio cuando Gelman encuentra en la tradición mística judeocristiana la condición de lo que él llama "vivencia exiliar", y la tradición bíblica se vuelve a partir de ese momento central en sus poemas. Así, Citas y comentarios (escrito entre 1978 y 1979) está construido a través de la intertextualidad con la mística renacentista de San Juan y Santa Teresa; Dibaxu (escrito entre 1983 y 1985) contiene poemas en ladino, lengua de exilio por antonomasia: hablada por los judíos sefaradíes primero, y tras su expulsión en 1492, lengua de la diáspora; por su parte, en Com/posiciones (escrito entre 1984 y 1985), Gelman incluye traducciones de poetas judeo-españoles y versiones basadas en distintas fuentes bíblicas.

Mi hipótesis es que la reescritura que realiza de diversos textos, más allá del imaginario bíblico que la origina e incluso más allá de una intertextualidad entendida en el sentido clásico de Gérard Genette, se corresponde con un aspecto estructural de la transmisión de la herencia judía a través de la cual Gelman restauraría el hilo roto de la tradición, inscribiéndose en ella.

Si bien mi intención no es definir a Gelman como escritor judío, y mucho menos encerrarlo en una supuesta categoría de literatura judía, me gustaría recordar su propia declaración según la cual lo judío forma parte de su subjetividad y alienta su escritura: "me resulta imposible, en mi caso, definir lo judío que constituye mi subjetividad y que, sin duda, alienta en lo que escribo" (1992: 89). Me interesa esta declaración porque curiosamente es análoga a la que desde el psicoanálisis permite a Freud afirmar que, aunque sin poder definirlo en "términos claros", lo judío es "esencial" para el desarrollo de su teoría (Freud 1993: 67); o desde la filosofía, en la línea de Levinas, para quien el judaísmo consiste en una exigencia ética radical, Derrida puede también referirse a la imposibilidad de precisar la dimensión judía que sin embargo reconoce como determinante en su pensamiento, autoproclamándose el "último de los Judíos". Es decir, desde distintos tipos de discursos no religiosos como son la literatura, el psicoanálisis o la filosofía, se expresa a lo largo del s. XX la misma dificultad por determinar el alcance objetivo de lo judío en las obras, si bien se reconoce como parte esencial en la esfera más subjetiva y personal. Como si desde la modernidad hubiera que reinventar el lugar de lo judío a partir de discursos seculares -y vinculado en cada caso a una subjetividad-; pero como si paradójicamente fuera desde el seno mismo de la tradición que surgiera esa posibilidad de invención. En el caso de Gelman esto se hace evidente, por ejemplo, en Carta a mi madre (1984-1987), cuando tras la muerte de su madre se pregunta:

[...]

siempre supiste lo que hay entre nosotros y nunca

me dijiste/¿por culpa mía?/¿te reproché todo el 
tiempo que me expulsaras de vos?/¿ése es mi exilio verdadero?/¿nos reprochamos ese amor que se buscaba por separaciones? [...]

[...] ¿tu padre?/¿ese

rabino o santo?/¿que amabas?/¿más que a mí?/

¿me perseguías porque no supe parecerme a él?/

¿y cómo iba a parecerme?/¿no me querías otro?/

$[. .$.$] ¿soy planta que no ve sus raíces?$

La confrontación con su herencia judía que en cierto modo lo enfrenta a su vez con la madre, parece permitirle, paradójicamente, afirmarse y reconocer su herencia en esa misma separación. Porque tal vez en estos versos el reproche que dirige a su madre no se refiere tanto a la imposición de una tradición, la ley judía representada por el abuelo de una tradición de rabinos interrumpida por el poeta; tal vez el reproche a la madre alude como el de Kafka en su carta al padre- al hecho de no haberle sabido (podido) transmitir la Ley. La diferencia fundamental entre Gelman y Kafka es que mientras esta ruptura es irreconciliable entre Kafka y su padre, la relación entre Gelman y su madre parece basarse en el reconocimiento íntimo de esa separación, la aceptación de la diferencia, como único encuentro posible entre los dos.

Ahora bien, desde el exilio, Gelman recupera lo judío más allá de la anécdota personal y familiar de una subjetividad que nutre sus poemas. Se trata, como veremos, de un reencuentro con la tradición, que elaborará, desde su lugar de poeta argentino, reinventándola al tiempo que la transmite en sus versos.

\section{Las raíces más profundas y exiliadas de la lengua}

Más allá de las referencias temáticas, el exilio se convierte a partir de ese momento, como señalé, en un componente estructural de su búsqueda poética, de la experimentación con la lengua. Dos son los libros fundamentales en este sentido, que me interesan por estar el exilio estrechamente asociado al componente judío: por una parte, Dibaxu, donde el exilio de la lengua se lleva a cabo a través del pasaje por la escritura en ladino y del procedimiento de auto traducción a su lengua natal, el argentino. El exilio y la traducción son por lo demás dos mecanismos muy próximos en Gelman, que permiten establecer una continuidad entre su obra anterior y posterior a su propio exilio ${ }^{10}$. Por otra parte, la "visión exiliar" es el núcleo de Com/posiciones, libro que compila reescrituras o traducciones libres, adaptaciones, principalmente de textos de poetas judeo-españoles de la Edad Media aunque también hay otros poemas de procedencia bíblica ${ }^{11}$. Hay que señalar que junto a esas reescrituras de poetas judeo-españoles, en el lugar central del poemario, aparece un heterónimo, Eliezer ben Ionon, a quien asigna el mayor número de poemas (11). Aunque lo sitúa en una cronología y una geografía alejadas en el tiempo y el espacio (mainz-toledo-provenza 1130-1187), el nombre constituye una alusión directa a su hijo (ben Jonon en hebreo significa literalmente hijo de Juan) ${ }^{12}$, dato que resulta fundamental para comprender la "visión exiliar" fundadora del libro, como comprenderemos.

En el exergo inicial, Juan Gelman se preocupa por explicar la idea de "composiciones" que constituye el título en este sentido:

llamo com/posiciones a los poemas que siguen porque los he com/puesto, es decir, puse cosas de mí en los textos que grandes poetas escribieron hace siglos. está claro que no pretendí mejorarlos, me sacudió su visión exiliar y agregué -o cambié, 
caminé, ofrecí- aquello que yo mismo sentía. ¿cómo contemporaneidad y compañía? ¿mía con ellos? ¿al revés? ¿habitantes de la misma condición?

en todo caso, dialogué con ellos. como ellos hicieron conmigo desde el polvo de sus huesos y el esplendor de sus palabras

Según María del Carmen Sillato, “desde su exilio en Europa, Gelman buscó caminos que le ayudaran a sobreponerse al dolor de las pérdidas y lo acercaran a ése, su país natal, del que había sido expulsado." (2000: 428). Para ella, la "visión exiliar" que motiva el poemario tiene que ver desde esta óptica con la presencia-ausencia que caracteriza tanto a la mística cristiana (con la figura del amado ausente) como a la mística judía de la Cábala (donde Dios es el gran ausente). Así, Sillato propone que esta tradición confluye en los poemas de Gelman a través de la imagen del país ausente desde el exilio en el que escribe $^{13}$. Para Pablo Gasparini, por su parte, la visión exiliar de Gelman responde, ante todo, a un trabajo concreto de búsqueda de un sustrato de la lengua. Refiriéndose a Dibaxu , Gasparini define la lengua de abajo a la que alude el título, "sustrato o fundamento" como el elemento extranjero inherente a la propia lengua. Así, cuando Gelman expresa en el escolio que sirve de prefacio a Dibaxu su intención de buscar las raíces "más profundas y exiliadas de la lengua" (7), en realidad no le interesa el origen primero de una lengua en el que asentar sus bases, sino, según sus propias palabras, "el estado naciente" de la lengua, que es todo lo contrario (Sillato 2000: 429) ${ }^{14}$. El estado naciente de la lengua es necesariamente anterior a la cristalización del idioma español, se trata de una lengua que todavía da cuenta del espesor que la constituye. Dicho de otro modo, es una lengua que prefigura y da cabida a todas las potencialidades que ella misma contiene, incluidas las variedades dialectales más modernas, como expresiones del argentino oral que por lo demás Gelman suele utilizar en sus poemas. Según esta idea, para Gelman "la lengua es mucho más que una cosmovisión. Tiene un inconsciente, depósito de siglos. [...] En ese inconsciente de la lengua se aloja todo lo judío que cabe en la lengua castellana". Por eso, al referirse a la lengua de los poetas judeo-españoles medievales que incluye en Composiciones, también escribe que: "Todos nosotros somos hablados por esa lengua, y lo extraordinario es que otras lenguas, las lenguas del exilio, desembocan en el gran río del idioma de los argentinos" (1992: 84 y 85).

Según ello es importante señalar que los poemas de Com/posiciones no se presentan en la compilación mediante un orden cronológico, sino que las temporalidades y geografías se combinan haciéndolos coexistir en otro tiempo fuera de la linealidad que caracteriza a la cronología histórica. Gelman rompe con toda cronología porque no le interesa reconocer un origen a sus poemas, de los que serían reescrituras posteriores, sino al contrario provocar el encuentro entre las distintas voces y temporalidades para hacer estallar ese inconsciente que la lengua contiene y volverlo palpable en sus versos ${ }^{15}$. Es curiosamente la misma concepción de la tradición donde según la exégesis rabínica, caben los anacronismos ${ }^{16}$ porque el supuesto origen de un texto primero es inaccesible, al igual que su autoría, y al mismo tiempo está contenido a través de las múltiples versiones y voces que van construyendo la cadena de la transmisión. La exégesis rabínica considera en efecto que el sentido del texto sagrado no está dado y se construye sólo en la dialéctica entre el texto y su interpretación ${ }^{17}$, de modo que cuando los comentarios que constituyen la interpretación del Talmud se van añadiendo unos a otros se crea un movimiento incesante de mise en abyme que no puede ser, por tanto, acumulativo ni lineal en la medida en que se trata siempre de un retorno perpetuo sobre sí mismo y a la vez una apertura infinita de lecturas ${ }^{18}$. Gelman parece hacer de este principio su propia poética y es lo que 
expresa al evocar un sueño que alude a uno de los poemas de Com/posiciones ("Oración" de Yehuda Halevi):

A veces tengo un sueño maravilloso: que alguien vuelva a partir de este poema mío, que prolonga una escritura de hace nueve siglos que es eco de otra de tres siglos antes. Porque la poesía es infinita y es dado sentir su infinitud, por la que hombres y nombres pasan con la fugacidad de un leve resplandor, sellados por el deseo de alimentarla y alimentarse de ella. (1992: 89)

Del mismo modo que para la tradición judía ningún texto significa por sí mismo ni contiene un sentido absoluto, los poemas en Com/posiciones se construyen en el diálogo de unos con otros. La intertextualidad que caracteriza al poemario de Gelman puede leerse entonces a través de este mismo proceso de transmisión. De este modo con la incorporación de la tradición judía a sus versos Gelman confiere espesor a la propia lengua y tradición argentinas, que no aparece desligada de la anterior.

Finalmente, es también así como cobra todo su valor la figura del heterónimo, Eliezer Ben Ionon, ya que al asociar a su hijo entre los poetas de otras épocas, Gelman suelda el hiato histórico; a pesar del salto generacional y de la muerte -recordemos que Marcelo Ariel Gelman había sido asesinado por los militares antes de la escritura de estos poemas-, Gelman restaura la filiación en su doble dirección: esto es, la filiación de Juan Gelman respecto a la tradición judía de sus padres y la filiación del hijo muerto respecto del mismo Juan Gelman. En otras palabras, lo proyecta hacia el pasado de la "lengua naciente" entre otros nombres de la tradición, con Eliezer Ben Ionon reaviva el pasado a la vez que recupera un futuro arrebatado. Es lo que expresa Gelman en otros versos dedicados a su hijo : "El pensamiento insiste en traerte / y devolverte a lo que nunca fuiste." El judaísmo en Gelman abre así nuevas puertas a la utopía.

\section{La intertextualidad restringida}

A través de la intertextualidad en la obra de Gelman reconocemos, por un lado, la modalidad de transmisión de la tradición judía; pero además, la intertextualidad consiste en una técnica muy precisa a la que el poeta alude de manera explícita. En su texto "Lo judío y la literatura en castellano", Gelman se refiere a la "intertextualidad restringida" para designar la técnica con la que los poetas hebreos de la escuela del Al-Andalus del siglo XIII citaban la Biblia en sus poemas ${ }^{19}$. Esta técnica consistía en "la inserción en sus poemas de textos bíblicos, desde una frase corta hasta un versículo entero, entretejidos hábilmente en el texto del poema. La cita bíblica podía ser textual, ligeramente alterada o elíptica, y creaba una vasta gama de efectos de significado que a veces contradecía al del original" (87). Esto mismo que hacían los poetas de la escuela de Al-Andalus con la cita bíblica es lo que hace Gelman con los textos bíblicos y de la tradición judía en Com/ posiciones. De manera general, Gelman despoja a estos poemas de toda referencia explícita a la Biblia o a la historia bíblica para limitarla a los paratextos; así, por ejemplo, en el poema "La petición" de Salomón Ibn Gabirol la invocación inicial al "Señor" (con mayúscula) se convierte en un "vos" con minúscula. 0 en "La puerta", del mismo poeta, elimina toda referencia a Hagar, la madre de Ismael.

De manera más concreta, Gelman procede a desplazamientos de las referencias bíblicas incluidas en los poemas: en lugar de retomar el mismo versículo o cita que retoma el poeta medieval Gelman selecciona otro, lo segmenta, o simplemente modifica la estructura sintáctica en que aparece. Pero sobre todo, mientras la novedad en los poetas 
de la escuela del Al-Andalus consistía en entretejer la cita bíblica con sus textos, Gelman construye sus poemas a partir de los de ellos y provoca el cruce o encuentro entre épocas, lenguas y voces que en el exergo identificaba con la "contemperaneidad y compañía". El resultado de esta intertextualidad restringida, de las citas o traducciones que incorporan la modificación mínima, constituye su hiddush (del hebreo שiּṬ: innovación), a través del cual Gelman ofrece un sentido completamente nuevo al poema y con él, a la tradición. Refiriéndose a la reescritura de textos bíblicos en otros poemas de Gelman, Geneviève Fabry escribe en este sentido:

[...] al reescribir los principales textos sagrados del judaísmo y del cristianismo, no cancela la oposición entre textos sagrados y profanos banalizándolos, sino que al contrario opera un desplazamiento de sus fuerzas respectivas: da a la experiencia del exilio latinoamericano una hondura lingüística y metafísica insospechada; inversamente, otorga a las quejas de amor de los místicos castellanos o bíblicos una actualidad desconcertante [...] (311-312)

Si este "desplazamiento de fuerzas" es posible, si existe encuentro entre las distintas voces, es porque mediante su reescritura, Gelman actúa -una vez más- contra la lectura cronológica y lineal de la tradición.

Terminaré con dos ejemplos de poemas asignados a Ibn Gabirol, poeta de la escuela del Al-Andalus, para ilustrar el mecanismo. Comparemos en primer lugar las dos versiones de "La puerta", a partir de la versión inglesa que al parecer Gelman habría utilizado (según Sillato 1996: 150):

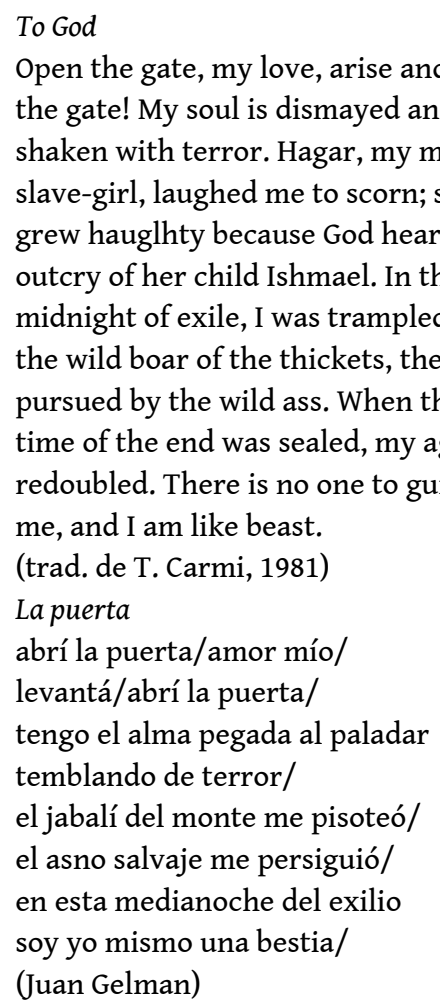

Por una parte, el poema de Ibn Gabirol (poeta de la escuela del Al-Andalus) ya se inicia con una inversión de la situación del Cantar de los cantares en el que se inspira, ya que en lugar de la voz del amado pidiendo a la amada que le abra la puerta, es la voz femenina representante de la congregación de Israel la que pide al Señor que le abra la puerta para ayudarla en el exilio. En la versión de Gelman la huella del Cantar y del Éxodo subsisten mediante algunas imágenes, vocablos, que sin embargo han perdido ya toda 
referencialidad primera (la puerta, la medianoche del exilio, el jabalí...); pero además, Gelman transforma una imagen del poema de Ibn Gabirol de modo que vuelve visible otra, esta vez de los Salmos, y que estaba ausente en el poema de Gabirol. Así, en lugar del alma temblando ("Muy soul is dismayed and shaken" en versión de De Carmi), Gelman escribe "el alma pegada al paladar", en evocación evidente a los Salmos 22 y 137 ("Tengo reseca la garganta y la lengua pegada al paladar" (22:15) y "Que se me pegue la lengua al paladar si no me acuerdo de Ti" (137:26), respectivamente). El texto bíblico así evocado mediante asociaciones y correspondencias veladas densifica su tejido al mismo tiempo que, al cambiar de referencia bíblica, enriquece el sentido del poema.

En "La pérfida", al borrar un verso y añadir otro en su lugar Gelman cambia completamente el sentido del poema.

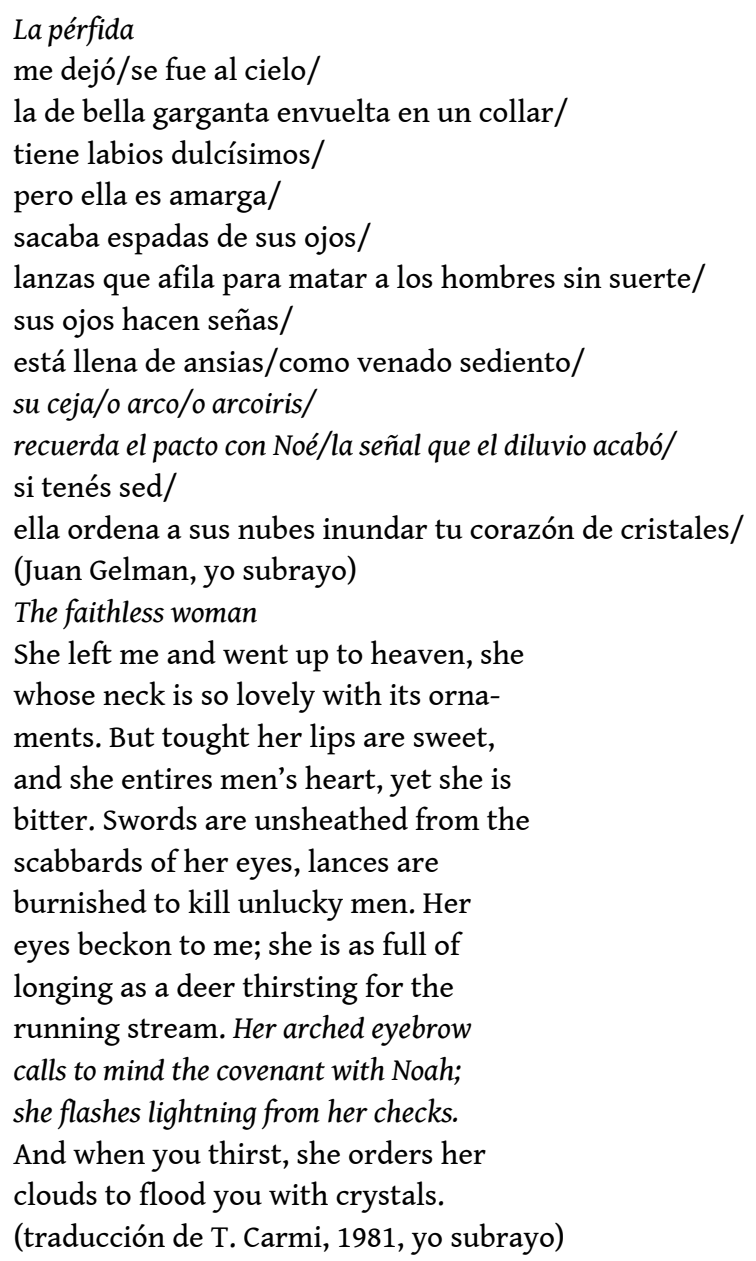

Donde Gabirol escribe: "Her arched eyebrow/calls to mind the covenant with Noah;/ she flashes lightning from her checks" (en version de Carmi), Gelman escribe: "su ceja/o arco/o arcoiris/ // recuerda el pacto con Noé/la señal que el diluvio acabó/". Es así que, por un lado, mediante la introducción de los tres términos con la disyuntiva en el primer verso citado, Gelman logra crear un efecto fónico y visual de mayor reverberancia, que la simple imagen de las cejas arqueadas; por otro, Gelman elimina el verso que podría traducirse literalmente al español como "ella destella alumbrando desde sus mejillas", y en su lugar escribe "la señal que el diluvio acabó". En primer lugar, este cambio insiste en el componente bíblico: Gelman transforma la imagen tradicional de la mujer con las cejas arqueadas y las mejillas destelleantes en la evocación al arco y arcoiris de Noé; en segundo lugar, además, Gelman permite interpretar el pacto con Noé y el diluvio de dos 
maneras opuestas, según leamos "la señal que el diluvió acabó" como aposición del pacto o como complemento del verbo "recordar": en el primer caso, el pacto es la señal de que el diluvio se había acabado, mientras que en el segundo, ofrece una interpretación fuera de la cronología del relato bíblico según la cual el diluvio habría borrado la señal dando lugar al fin del pacto. Mediante esta ambivalencia sintáctica, Gelman ofrece al lector la posibilidad de interpretar la vigencia o no del pacto de la Alianza. Esta ambivalencia en lectura del poema gelmaniano es por lo demás posible si se tienen en cuenta las variantes del español, pues la lengua argentina suele elidir la preposición regida por el verbo, exigida en cambio por la norma peninsular (la señal de que).

Para concluir, en primer lugar debemos recordar que lo judío no aparece en Gelman desligado del resto de intertextualidades e influencias que constituyen su experiencia vital, cultural y lingüística. Y si como señalamos al principio lo judío se vuelve explícito tras el exilio, no se trata, como vimos, ni de reinvindicar una pertenencia ni de revelar los contenidos de una enseñanza; en realidad Gelman se inserta en la tradición y participa de su transmisión a través de la intertextualidad y la reescritura. Son pues procedimientos formales y lingüísticos los que le permiten crear una nueva temporalidad en el poema y con ella dar cabida a las distintas potencialidades de la tradición, esto es a las distintas lecturas que de ella emanan. La dimensión judía pasa a formar parte de este modo de la tradición argentina que Gelman representa con su escritura.

\section{BIBLIOGRAFÍA}

Agamben Giorgio, El fuego y el relato, Madrid, Sexto piso, trad. Ernesto Kavi, 2016.

Arendt Hannah, Between Past and Future. Eight Exercices in Political Thought [1961], Londres, Penguin Books, 1968.

-- La vie de l'esprit, Paris, PUF, 1981.

Benjamin Walter - Scholem Gershom, Théologie et utopie. Correspondance 1933-1940, Paris, Éditions de l'éclat, trad. Didier Renault y Pierre Rusch, 2010.

Derrida Jacques, “Abraham, l'autre”, en Judéités. Questions pour Jacques Derrida, dir. Joseph Cohen et Raphael Zagurly-Orly, Paris, Galilé, 2003, p. 11-42.

-- Le dernier des Juifs, Paris, Galilé, 2014.

Fabry Geneviève, Las formas del vacío. La escritura del duelo en la poesía de Juan Gelman, AmsterdamNew York, Rodopi, 2008.

Freud Sigmund, Prefacio a la edición hebrea de Totem y tabú, en Totem et tabou, Paris, Gallimard, 1993, p. 67.

Gasparini Pablo, Dibaxu de la lengua: Gelman en sefardí, Cadernos de língua et literatura hebraica, № 11, 2013. En línea: https://www.revistas.usp.br/cllh/article/download/83505/86453 [Consultado en septiembre 2018].

Gelman Juan, “Lo judío y la literatura en castellano”, en Hispamérica № 62, 1992, p. 83-90. 
-- Dibaxu, Buenos Aires, Espasa Calpe/Seix Barral, 1994.

-- Composiciones, en Interrupciones 2, Buenos Aires, Seix Barral, 1998, p. 149-212.

-- Carta a mi madre, Buenos Aires, Libros de Tierra Firme, 1989.

Goldberg Florinda F., "Literatura judía latinoamericana: modelos para armar”, en Pluralismo e identidad. Lo judío en la literatura latinoamericana, Buenos Aires, Mila, 1986, p. 309-324.

Kovadloff Santiago, "Eliahu Toker", en El imaginario judío en la literatura de América Latina. Visión y realidad, San Pablo, Grupo Editorial Shalom, 1990.

Levinas Emmanuel, Difficile liberté [1963], Paris, Albin Michel, 2012.

Memmi Albert, Penser à vif: de la colonisation à la laïcité, textos reunidos por Hervé Sanson, Paris, Non Lieu, 2017.

Mosès Stéphane, “Quelques principes de l'herméneutique rabbinique”, en Le temps de la Bible, Paris, éditions de l'éclat, 2011a, p. 123-140.

-- “Typologie de la modernité juive”, en Le temps de la Bible, Paris, éditions de l'éclat, 2011b, p. 141-156. Ver traducción al castellano en este número de Cuadernos Lirico.

Senkman Leonardo, "La nación imaginaria de los escritores judíos latinoamericanos", en Revista Iberoamericana, № 191, abril-junio 2000, p. 279-298.

Sillato María del Carmen, Juan Gelman: las estrategias de la otredad. Heteronimia, intertextualidad, traducción, Buenos Aires, Beatriz Viterbo, 1996.

-- “Dibaxu de Juan Gelman: la poesía desde las 'exiliadas raíces de la lengua”, en Actas del XXIII congreso AIH, vol. III, Madrid, Castalia, 2000, p. 428-434.

Sosnowki Saúl, "Sobre el inquiétante y definitorio guión del escritor judío-latinoamericano", en Pluralismo e identidad. Lo judío en la literatura latinoamericana, Buenos Aires, Mila, 1986, p. 31-43.

-- La orilla inminente. Escritores judíos argentinos, Buenos Aires, Legasa, 1987.

Yerushalmi Yosef Hayim, Zahor. Histoire juive et mémoire juive [1982], Paris, Gallimard, 2008.

Zard Philippe De Shylock à Cinoc. Essai sur les judaïsmes apocryphes, Paris, Classiques Garnier, 2018.

\section{NOTAS}

1. Char René, Fureur et mystère, Feuillets d'Hypnos, 62, 1946, p. 190: “Notre héritage n'est précédé d'aucun testament". Traducción mía.

2. Citado por Stéphane Mosès en Temps de la Bible, p. 146. Traducción mía.

3. "Without testament or, to resolve the metaphor, without tradition -which selects and names, which hands down and preserves, which indicates where the treasures are and what their worth is- there seems to be no willed continuity in time and hence, humanly speaking, neither past nor future, only sempiternal change of the world and the biological cycle of living creatures in it." (1968: 5, traducción mía)

4. Para Yosef Hayim Yerushalmi, la Emancipación significó la desorientación y todo Judío se encuentra perdido desde entonces (1984).

5. Cuando Benjamin escribe a Scholem que para los personajes de Kafka la verdad es inalcanzable, Scholem precisa que se trata en realidad de que ya no entienden la Ley, aunque siguen estando sometidos a ella. Esta idea también es retomada por Mosès en el artículo traducido para este número de Lirico. 
6. Mientras en el caso europeo la asimilación oponía judaísmo religioso y judaísmo social e intelectual, así como campo y ciudad, en América Latina, en cambio, la asimilación no supuso un conflicto religioso. Cf. artículo de Leonardo Senkman publicado en este número.

7. Sobre la distinción entre judaísmo y judeidad, recomiendo la lectura "Abraham, un autre", de Derrida (ver bibliografía).

8. Citado de El fuego y el relato de Agamben (2015: 11). Allí el filósofo italiano propone una lectura de este midrash mediante una metáfora: mientras el fuego representa el misterio, el secreto, lo indecible, el relato se corresponde con la forma en la que, a través de la lengua, siguen subsistiendo sus huellas.

9. En la línea de Levinas, para quien el judaísmo se traduce por una exigencia ética radical ( Difficile libérté), Derrida se autoproclama "el último de los Judíos" y reflexiona sobre la imposibilidad de asignar a su judaísmo otra cosa que la "responsabilidad sin límite" a "asumir la herencia de generaciones": "comme si c'était celui qui désavoue le plus, écrit-il, et qui semble trahir les dogmes de l'appartenance communautaire, religieuse, voire celle du peuple, de la nation et de l'État, etc., comme si celui-là seul représentait l'exigence dernière, la requête hyperbolique de cela même qu'il semble trahir en parjurant." (Judéités, op. cit., p. 21)

10. Reenvío en este sentido a mi artículo "Mort et résurrection dans le poème. La traduction de Juan Gelman à Jacques Ancet", en Roland Béhar y Gersende Camenen ed., Traduction France/ Argentine, Éditions rue d'Ulm. En prensa.

11. Además de 26 poemas de distintos poetas judeo-españoles de los siglos X al XVI, hay un poema árabe (que abre el conjunto de manera significativa, puesto que la poesía árabe fue fundamental para la renovación de la poesía hebrea), un poema de un rabino de la época del segundo Templo (s. I), un anónimo provenzal, 2 himnos hekhalot (himnos compuestos en Palestina y Babilonia entre los siglos III y IV), 2 textos procedentes de los rollos del mar muerto y otros 7 poemas atribuidos a profetas y personajes bíblicos (como Amós, Ezequiel, Job, o el David de los salmos).

12. Eliezer, por su parte, podría evocar al gran Rabbi Eliezer, probablemente la figura más importante de la Mishná, esto es de la tradición de exégesis rabínica. Más cerca en el tiempo, Eliezer Ben-Yehuda (imperio ruso 1858- Jerusalem 1922) fue el responsable de la renovación de la lengua hebrea moderna. Tal vez no haya que identificar el nombre del hetéronimo con ninguno de los dos o, aún mejor, haya que asociarlo a los dos al mismo tiempo. La raíz, Liezer, significa etimológicamente "Dios es mi ayuda" y, en cualquier caso, la elección del nombre para el heterónimo, figura central del poemario, no parece arbitraria.

13. En Las formas del vacío. La escritura del duelo en la poesía de Juan Gelman (2008), Geneviève Fabry se refiere al duelo de manera más general y con una dimensión más abstracta.

14. Entrevista citada por Sillato. Escribe Gelman en otro lugar: "Y lo que a mí francamente me fascina de los textos de Santa Teresa, de San Juan, de Fray Luis y de tantos otros -Quevedo, por ejemplo-, es justamente el manejo del idioma naciente; manejo que también tenían Cólón, Hernán Cortés y demás" Sobre Santa Teresa, por lo demás, recuerda que "el mismo nombre de Teresa es nombre de conversa, un anagrama que oculta el nombre de Ester" (1992: 85).

15. Porque no hay un texto original no hay un origen único de cada reescritura. Es lo que demuestra por ejemplo Geneviève Fabry al referirse a la reescritura de los salmos, que no corresponden en realidad con ningún salmo específico, sino que, se basan en varios de ellos, construyéndose como textos nuevos cada vez.

16. Es célebre el midrash según el cual muchos nos después de la revelación de las tablas de la Ley, Moisés se aparece como discípulo de Rabbi Akiva y le pregunta sobre unas enseñanzas que él habría transmitido y que sin embargo ya no le pertenecen y no entiende.

17. Se trata del círculo hermenéutico del Talmud, que Mosès explica del siguiente modo: "Mais cette postulation [de sens] ne se fonde pas sur les intentions supposées de l'inspirateur divin de la Bible (pourquoi Dieu ne se contredirait-il pas?) ou sur celles de Moïse, à qui la tradition juive 
attribue sa rédaction, mais sur le texte lui-même, ou plus exactement sur la dialectique du texte et de son interprétation. C'est en effet l'interprète qui projette sur le texte son exigence de cohérence [...] C'est là le fameux "cercle herméneutique" auquel les Maîtres du Talmud font allusion. [...] Pour la tradition juive, le sens de la Torah ne se dévoile pas en dehors de l'interprétation qui le fait apparaître. C'est pourquoi la lecture juive de la Bible est fondée sur le principe de la coexistence de deux formes de Torah : la Torah écrite (c'est-à-dire son texte) et la Torah orale (c'est-à-dire son interprétation). Toutes deux ont la même origine divine, toutes deux ont été données simultanément à Moïse au Mont Sinaï, et elles sont aussi indispensables l'une que l'autre à la constitution du sens de la Révélation." p. 126 " (2011a: 125-126).

18. "Commentaire d'un commentaire, le Talmud renvoie en permanence au texte biblique, dont il constitue une vaste exégèse.", escribe Stéphane Mosès (ibidem: 128).

19. Aunque Gelman toma el término de Ricardou, no se refiere exactamente a lo mismo, ya que para éste la interextualidad restringida corresponde a la interextextualidad entre los diferentes textos de un mismo autor: "Le texte n'émane pas, isolément, d'un auteur, en tant que stade actuel au cours des relatifs changements de sa vie. Il s'écrit résolument en relation avec les textes déjà écrits par le même signataire". Jean Ricardou, “Terrorisme, théorie”, p. 12-13, in Robbe-Grillet, colloque de Cerisy, U.G.E., 10/18, 1976.

\section{RESÚMENES}

A través del análisis de algunos poemas de Juan Gelman escritos durante el exilio, este artículo trata de demostrar cómo a partir de ese momento el poeta recupera un legado judío de manera explícita a través de diferentes técnicas y restaura así el "hilo roto de la tradición". Lo judío en Juan Gelman no se opone entonces a lo argentino sino que su escritura articula las dos herencias de modo que una y otra aparecen indisociables.

Cet article analyse quelques poèmes de Juan Gelman écrits pendant son exil politique afin de montrer que c'est à partir de ce moment que le poète récupère un héritage juif resté invisible auparavant. Au moyen de différentes techniques poétiques, Gelman restaure ainsi le "fil rompu de la tradition". La dimension juive ne s'oppose pas à la tradition argentine, car l'une et l'autre sont articulées dans ses vers de façon à devenir indissociables.

Through the analysis of several poems written by Juan Gelman during his political exile, this article demonstrates that this event triggered a change in the poet's work: he started to reclaim a Jewish legacy which had been overlooked until now. Using a diversity of poetic devices, Gelman reconnected the "broken thread of tradition." The Jewish aspect is not incompatible with the Argentine tradition, for both are interwoven in the lines of his poems, so that they become inseparable.

\section{ÍNDICE}

Keywords: Juan Gelman, Judaism, exile, rewriting, transmission

Mots-clés: Juan Gelman, judaïsme, exil, réécriture, transmission

Palabras claves: Juan Gelman, judaísmo, exilio, reescritura, transmisión 
AUTOR

VALENTINA LITVAN

Université de Lorraine (Metz) - ECRITURES EA 3943

valentina.litvan@univ-lorraine.fr 